\title{
Management of Gallstones and Acute Cholecystitis in Patients with Liver Cirrhosis: What Should We Consider When Performing Surgery?
}

\author{
Shang Yu Wang, Chun Nan Yeh, Yi Yin Jan, and Miin Fu Chen \\ Department of General Surgery, Chang Gung Memorial Hospital, Chang Gung University, Taoyuan, Taiwan
}

\author{
Article Info \\ Received February 10, 2020 \\ Revised June 19, 2020 \\ Accepted July 27, 2020 \\ Published online September 15, 2020 \\ Corresponding Author \\ Chun Nan Yeh \\ ORCID https://orcid.org/0000-0003-1455-092X \\ E-mail yehchunnan@gmail.com
}

\begin{abstract}
Acute cholecystitis and several gallbladder stone-related conditions, such as impacted common bile duct stones, cholangitis, and biliary pancreatitis, are common medical conditions in daily practice. An early cholecystectomy or drainage procedure with delayed cholecystectomy is the current standard of treatment based on published clinical guidelines. Cirrhosis is not only a condition of chronically impaired hepatic function but also has systemic effects in patients. In cirrhotic individuals, several predisposing factors, including changes in the bile acid composition, increased nucleation of bile, and decreased motility of the gallbladder, contribute to the formation of biliary stones and the possibility of symptomatic cholelithiasis, which is an indication for surgical treatment. In addition to these predisposing factors for cholelithiasis, systemic effects and local anatomic consequences related to cirrhosis lead to anesthesiologic risks and perioperative complications in cirrhotic patients. Therefore, the treatment of the aforementioned biliary conditions in cirrhotic patients has become a challenging issue. In this review, we focus on cholecystectomy for cirrhotic patients and summarize the surgical indications, risk stratification, surgical procedures, and surgical outcomes specific to cirrhotic patients with symptomatic cholelithiasis. (Gut Liver 2021;15:517-527)
\end{abstract}

Key Words: Gallbladder stone; Cholelithiasis; Cirrhosis; Cholecystectomy; Laparoscopy

\section{INTRODUCTION}

Cirrhosis is one of the most complex human diseases and causes significant physiological changes, local anatomical alterations, immune status modifications, and other associated risks, which influence the life expectancy of patients. Cholelithiasis, a common medical condition, has been recognized to have a higher incidence in cirrhotic patients than in the general population. ${ }^{1}$ Currently, surgical treatments, laparoscopic cholecystectomy (LC) or open cholecystectomy (OC) via laparotomy are the standard of care for symptomatic gallbladder stones (GB stones), including cases with repeated episodes of pain, gallbladder polypoid lesions, choledocholithiasis with or without cholangitis, acute cholecystitis, and biliary pancreatitis. Without definite surgical treatment, the incidence of symptom relapse is high. ${ }^{2}$

Regarding surgical treatment for symptomatic GB stones in patients with cirrhosis, there are additional issues that should specifically be considered: (1) Should the surgical indication be modified? (2) Do we have any strategy to tackle the surgical difficulty that is increased in relation to local conditions such as the presence of abundant collateral vessels around the surgical field? (3) Similarly, how can we manage perioperative complications and improve surgical outcomes? In this review, we first summarize the pathophysiology of cholelithiasis in cirrhotic patients. Then, a thorough review of several relevant surgical issues, including surgical indications, surgical risks, surgical procedures, and surgical outcomes, is presented. Finally, we propose a suggested treatment flowchart for cirrhotic patients with symptomatic GB stones. 


\section{CHOLELITHIASIS IN CIRRHOTIC PATIENTS}

Cholelithiasis is a common condition in the general population. The prevalence of cholelithiasis is approximately $10 \%$ to $20 \%$, while symptomatic cholelithiasis occurs in approximately $20 \%$ of individuals with cholelithiasis. ${ }^{3}$ Cirrhotic patients, however, have been demonstrated to have a higher prevalence of cholelithiasis. ${ }^{4,5}$ In addition, the cumulative incidence has also been proven to be correlated with the course of cirrhosis progression, and this phenomenon reveals that a greater severity and a longer duration of cirrhosis increase the risk of cholelithiasis. ${ }^{1,6}$ Sheen and Liaw ${ }^{5}$ reported a Taiwanese cohort of healthy persons and chronic hepatitis B patients with or without cirrhosis (933 vs 500). According to their results, the prevalence of GB stones in cirrhotic patients was 4 to 5.5 times higher than that of healthy persons. In addition, the prevalence of GB stones increased along with increasing duration and severity of chronic liver diseases, with good linear correlation. In cirrhotic patients, the formation of black pigment stones surpassed that of cholesterol stones. Coelho et al. ${ }^{7}$ evaluated a series of patients undergoing liver transplantation. In Coelho's cohort, the prevalence of cholelithiasis in liver recipients was $24 \%$, while that in the control group was $9.5 \%$. Among patients with cholelithiasis, $86.2 \%$ had pigment stones.

Although the etiologies of cirrhosis, such as chronic viral hepatitis $\mathrm{C}$ and alcoholism, may increase lithogenesis, ${ }^{1,8}$ the deterioration of hepatic function in cirrhotic patients changes the biochemical environment of bile and, combined with other physiological changes, is the major causative factor, especially for black stones (Fig. 1). In cirrhotic patients, the compositions of secreted bile are changed, including decreased conjugated bilirubin, decreased phospholipid and bile acid production, and increased glycoprotein levels. ${ }^{3,6}$ The changes in bile composition enhance the nucleation of biliary stones. In addition, hemolysis is also an important contributor, and this coincides with the fact that black pigmented stones are the major type of stones found in cirrhotic patients. While portal hypertension-related hypersplenism may increase the destruction of erythrocytes (namely, hemolysis), a change in the cholesterol-to-phospholipid ratio of the erythrocyte membrane due to impaired hepatic function can alter the physiology, flexibility, and morphology of erythrocytes, increasing their destruction. ${ }^{9}$ Other factors, such as hypomotility of the gallbladder and increased enterohepatic circulation of unconjugated bilirubin, have also been proposed. The change in gallbladder motility has been confirmed by serial real-time ultrasonography and dynamic studies of gallbladder motility, and the extent of gallbladder smooth-muscle dysfunction has also been proven to be correlated with the severity of cirrhosis. ${ }^{10-12}$ Although the underlying mechanism is not well established, the observation of impaired motility of the gallbladder has been recognized to be a risk factor for cholelithiasis in cirrhotic patients based on currently published studies. ${ }^{10-12}$ Enterohepatic circulation occurs in the bowel segment of the

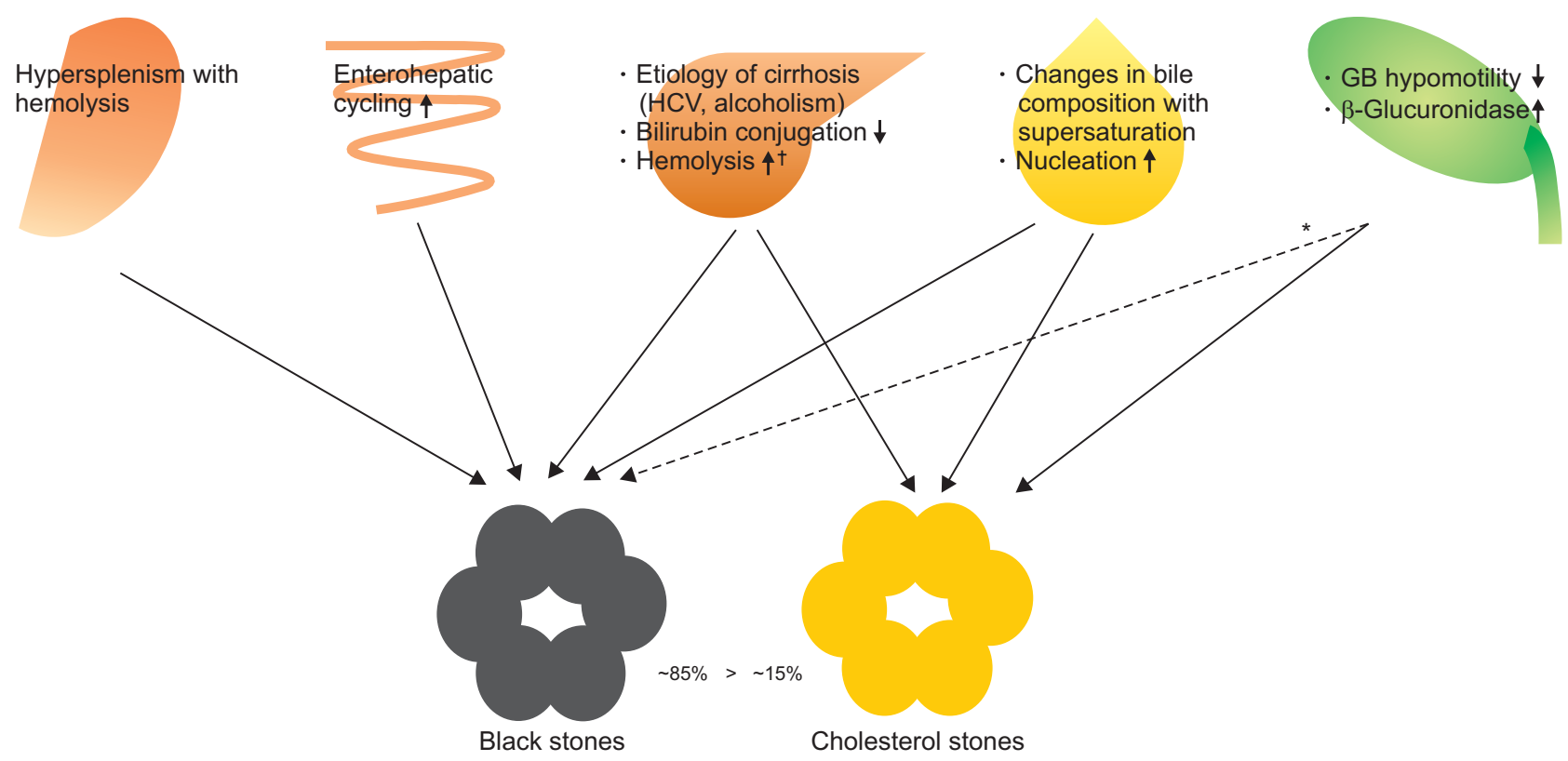

Fig. 1. Pathogenesis of cholelithiasis formation in cirrhosis. In cirrhotic patients, pigmented black stones are more common than cholesterol stones.

HCV, hepatitis C virus; GB, gallbladder. *The gallbladder-related effects contribute more significantly to cholesterol stone formation than black stone formation; ${ }^{+}$While hypersplenism related to portal hypertension causes the direct destruction of red blood cells, altered liver metabolism changes the components of their cell membranes. This effect facilitates hemolysis. 
distal ileum, and this physiologic process mainly facilitates bile acid absorption. ${ }^{13}$ Over $90 \%$ to $95 \%$ of secreted bile acid will be absorbed into the portal venous system and subsequently resecreted into bile. ${ }^{14}$ While alcoholism is one of the major etiologies of cirrhosis, alcohol consumption can also impair the absorption of bile acid, and this phenomenon further increases the bile acid concentration in the gastrointestinal tract. ${ }^{15,16}$ Intraluminal bile acid will increase the solubility of unconjugated bilirubin, further boost the absorption of bilirubin into the portal venous system, increase bilirubin secretion from the liver, and then heighten the risk of cholelithiasis. ${ }^{16}$ In summary, cirrhosis can influence the homeostasis of several physiological processes, and all these changes promote cholelithiasis in cirrhotic patients from different aspects.

\section{CHOLECYSTECTOMY IN CIRRHOTIC PATIENTS}

Most of the studies relevant to cholecystectomy in cirrhotic patients can be categorized into two periods: the pre-LC era and the LC era. The cutoff point is $1987 .{ }^{17}$ In this article, we extensively review the relevant studies. We focus on surgical indications, procedures, outcomes, and special perspectives related to cholecystectomy in cirrhotic patients. The relevant primary studies after 2000 are summarized in Table 1 .

\section{Surgical indications}

For patients with symptomatic cholelithiasis, several interventional procedures, including LC with or without bile duct exploration and endoscopic retrograde cholangiography and pancreatography (ERCP), can be conducted as either single or combined procedures. Since the de novo formation of common bile duct stones accounts for fewer than $10 \%$ of cases, ${ }^{18}$ most common bile duct stones are secondary stones from GB stones. Therefore, cholecystectomy, especially LC, is the definitive treatment for most cases of cholelithiasis. GB stones, according to the clinical presentation, can be categorized into three groups: (1) asymptomatic GB stones, (2) symptomatic GB stones without complications, and (3) symptomatic GB stones with complications, such as acute cholecystitis, common bile duct stones, or biliary pancreatitis. For asymptomatic GB stones, observational management is generally accepted for both cirrhotic and noncirrhotic patients. ${ }^{19}$ Maggi et al. ${ }^{20}$ reported a cohort of cirrhotic patients with a cholelithiasis prevalence of $38 \%$. In Maggi's cohort, the incidence of symptomatic GB stone development was $4.4 \%$ after a mean follow-up of 31.8 months with initially diagnosed cholelithiasis, and the annual rate of symptomatic GB stones with complications was less than $2 \%$. Although previous studies on the natural history of cirrhotic patients have revealed a relatively high incidence of GB stones, the progression to symptomatic conditions does not seem to be much different from that in general populations. ${ }^{19,21}$ Therefore, observational management is reasonable for cirrhotic patients with asymptomatic GB stones. Currently, no evidence supports prophylactic cholecystectomy for asymptomatic GB stones in cirrhotic patients. ${ }^{6}$

For cirrhotic patients with symptoms, the surgical indications of cholecystectomy, especially in the era of LC, have been generally adopted as being similar to those for the general population, except for patients with ChildTurcotte-Pugh (CTP) class C (see the following section). ${ }^{22}$ In addition, early cholecystectomy should be considered after patients are stabilized because later onset episodes of complications may impose a higher risk on these patients. ${ }^{23,24}$ Although LC is recognized as a safe procedure under emergency circumstances, even for cirrhotic patients, ${ }^{25}$ planned and elective LC should be the first choice for symptomatic GB stones.

\section{Risk stratification}

In the era before $\mathrm{LC}, \mathrm{OC}$ was the mainstream treatment for symptomatic GB stones, and the outcomes were catastrophic. ${ }^{26,27}$ In the era of LC, cholecystectomy has become a feasible procedure for cirrhotic patients. ${ }^{28,29}$ For decades, cirrhotic patients have been recognized as having high surgical risk. ${ }^{29-31}$ Therefore, preoperative risk stratification for cirrhotic patients is crucial to minimize postoperative complications. Several laboratory parameters ${ }^{32}$ and scoring systems, including the CTP score and the Model for EndStage Liver Disease (MELD), have been proposed as risk stratification measures for cirrhotic patients. ${ }^{33-36}$ The CTP score is the most prevalent tool for preoperative risk stratification. In patients with CTP class C, cholecystectomy is not recommended, and conservative treatment is suggested. Although catastrophic outcomes of OC for CTP class C patients were reported in the 1980s, there have been no case series reporting more than five CTP class C patients undergoing LC-intended procedures. Currò et al. ${ }^{37}$ reported a series of four patients with CTP class $\mathrm{C}$ cirrhosis, and a morbidity of $75 \%$ and a mortality of $50 \%$ was noted after 2000. For patients with CTP class C cirrhosis, alternative procedures, such as percutaneous cholecystostomy tube placement, should be considered the treatments of choice for symptom relief because of their relatively lower morbidity and higher safety. ${ }^{38,39}$ The surgical indications of cholecystectomy for CTP class C patients should only be justified under life-threatening conditions, such as diffuse peritonitis related to gallbladder rupture and hemorrhagic 


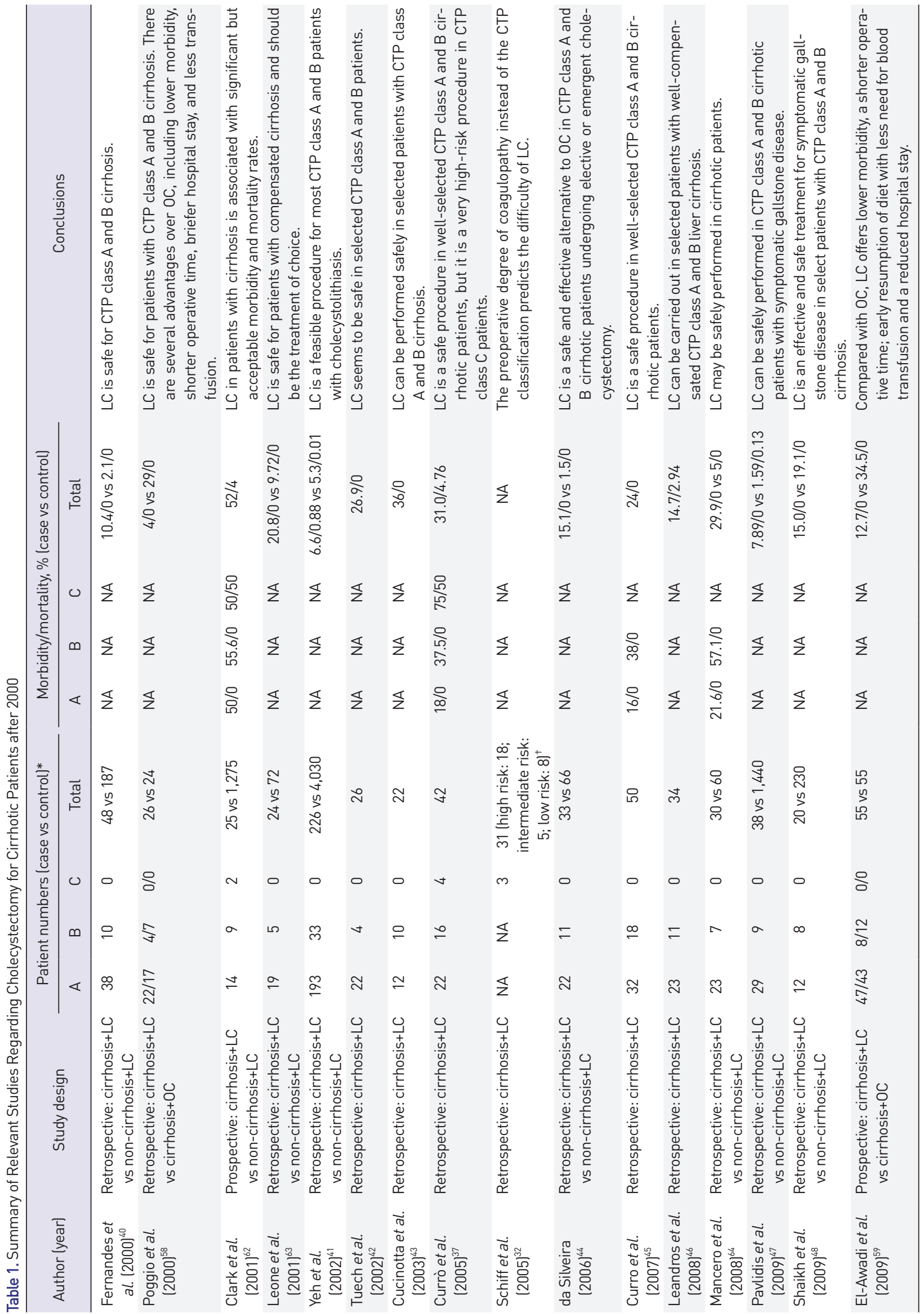




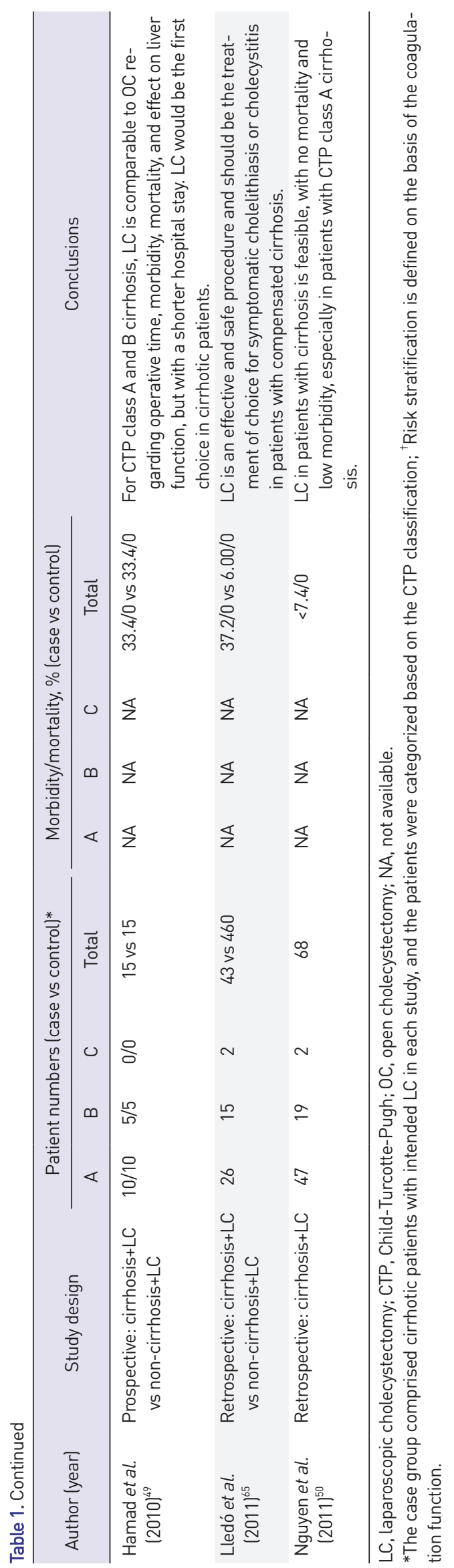

complications related to acute cholecystitis.

For CTP classes A and B, LC can be conducted once the surgical indication is justified and meticulous postoperative care is feasible, and most published studies have proven this fact. ${ }^{37,40-50}$ Nguyen et al. ${ }^{50}$ reported that there was no mortality or low morbidity of CTP class A patients (compared with patients in CTP classes B and C) after LC, and the surgical outcome of CTP class B was acceptable, as revealed in most of the published studies. Currently, the conclusions from most published studies are based on cohorts of CTP classes A and B. Although most of these studies were retrospective (Table 1), LC for CTP class A and B patients with justified indications is generally adopted.

The MELD score was proposed early in this century and was initially used to predict early death following elective transjugular intrahepatic portosystemic shunts and to help determine organ allocation priorities. ${ }^{51,52}$ The MELD score is a mathematical model that provides a more accurate prediction power than the CTP does. ${ }^{36}$ The cutoff value has not yet been established. While a previous retrospective study suggested a MELD score of 13 as a cutoff, ${ }^{36}$ realworld data published recently by Dolejs et al. ${ }^{53}$ suggested that a MELD score over 20 may predict a significantly high surgical mortality and morbidity. In the study conducted by Dolejs et al., ${ }^{53}$ the mortality of cirrhotic patients with MELD scores over 20 was $5.8 \%$, while the morbidity was $22.8 \%$. Another similar study from real-world data by Fleming et al. took ascites, combined with the MELD score, into consideration. In the study of Fleming et al., ${ }^{54}$ patients with MELD scores over 15 and ascites may have a mortality and morbidity of $23.53 \%$ and $47.06 \%$, respectively, if they undergo laparoscopic procedures. All of the relevant studies report that a high MELD score indicates a possibly high rate of surgical complications. In addition, there are several modifications of the MELD. Costa et al. ${ }^{55}$ conducted an interesting study regarding the predictive power of different MELD modifications and CTPs for cirrhotic patients undergoing surgical procedures. According to Costa's finding, the predictive powers of selected MELD modifications and three CTP-derived scores are similar in the area under the curve for surgical mortality ranging from $71 \%$ to $77 \%$. Since the practicality of CTP is superior to that of the MELD score and the accuracy of CTP is not much inferior to that of MELD, both scoring systems may be applied in preoperative risk stratification.

Some laboratory markers, including bilirubin, creatinine, international normalized ratio, and the platelet count, have been proposed as surrogates for preoperative risk stratification. ${ }^{32,33}$ However, all these factors reflect the severity of hepatic function impairment. In summary, for cirrhotic patients with planned cholecystectomy, precise 
evaluation of hepatic function is the most important preoperative evaluation in addition to other general preparations. Decompensated liver cirrhosis is the major contraindication for planned cholecystectomy. Surgical treatment for patients with decompensated liver cirrhosis is reserved for life-threatening conditions.

\section{Open cholecystectomy versus laparoscopic cholecystectomy}

Cholecystectomy has been considered a daunting procedure and can only be performed on cirrhotic patients under "really necessary" conditions. ${ }^{26}$ In 1985, Bloch et al. ${ }^{27}$ reported a series of 49 cirrhotic patients undergoing OC and cholecystostomy with a surgical mortality of $10.2 \%$ for all cases and 23.5\% for CTP class C cases. Since 1987, LC has been the standard treatment for gallbladder lesions. ${ }^{17}$ Although cirrhosis and portal hypertension have been contraindications for laparoscopic surgery, ${ }^{56}$ things have changed. Cholecystectomy performed in a laparoscopic fashion was considered and applied to cirrhotic patients due to its increased safety and superior postoperative outcomes (compared with those of open surgery) in the general population. ${ }^{57}$ In the last decade of the 20th century and first decade of the 21st century, several studies, most of which were retrospective, have proven that LC is superior to OC for a specific cohort of cirrhosis in terms of a shorter hospital stay, reduced operation time, lower morbidity, and less transfusion. ${ }^{49,58,59}$ Chmielecki et al. ${ }^{60}$ reported a nationwide population-based study from the Nationwide Inpatient Sample of Taiwan in 2011. According to these real-world data, patients with cirrhosis have increased inhospital morbidity and mortality after OC, and LC should be the preferred initial approach in cirrhotic patients. Laurence et al. ${ }^{61}$ and de Goede et al. ${ }^{31}$ published meta-analyses of randomized controlled trials to clarify the benefit of LC for cirrhotic patients in 2012 and 2013, respectively. Both of their studies supported the finding that LC is preferred over OC in terms of surgical complications and hospital stay. Therefore, LC, instead of OC, is currently the standard of treatment for selected cirrhotic patients with symptomatic GB stones.

The surgical outcome and safety of LC have been extensively studied compared to the corresponding measures in the general population. Several studies have compared cirrhotic patients with noncirrhotic patients after LC. ${ }^{40,41,44,47,48,62-65}$ While most of those studies were retrospective, Clark et al. ${ }^{62}$ conducted a prospective study in 2001 and concluded that LC in patients with cirrhosis is associated with significant but acceptable morbidity and mortality rates. Hemorrhage (8\%) and wound complications (24\%) were noted in Clark's report to have statistical significance compared with the corresponding outcomes in noncirrhotic patients. Although Clark's report was a prospective study, the patient number $(\mathrm{n}=25)$ was small. Most of the other relevant studies were retrospective. Our previous study in 2002 is the largest retrospective cohort to date, with 226 cirrhotic patients versus 4,030 noncirrhotic patients. ${ }^{41}$ The overall morbidity was $6.6 \%$ in cirrhotic patients, and the mortality was $0.88 \%$ (significantly different from noncirrhotic patients) in our series. We therefore concluded that LC is a feasible procedure for most Child class A and B patients with cholecystolithiasis. Other retrospective studies all claimed similar results and emphasized that LC is the surgical treatment of choice for selected cirrhotic patients with symptomatic GB stones (Table 1).

For cirrhotic patients, liver transplantation is always an option of treatment. Any abdominal surgery, especially hepatobiliary surgery, performed before transplantation may induce peritoneal adhesions, which in turn may increase the difficulty of future transplantation surgery. Polymeneas et al. ${ }^{66}$ reported a small series of 26 patients who underwent LC or OC (18 vs 8) with subsequent laparoscopic procedures. Both operative field and trocar entry sites were noted to show less adhesion in the LC group. This additional benefit would facilitate future transplantation surgery in cirrhotic patients after indicated cholecystectomy.

\section{Subtotal cholecystectomy}

The original idea of subtotal cholecystectomy can be traced back to the 19th century. ${ }^{67}$ In the 1950s, Madding ${ }^{68}$ suggested that subtotal cholecystectomy could be an alternative to conventional "total cholecystectomy" under circumstances of a difficult cholecystectomy and may be superior to complete cholecystectomy (constrainedly) and cholecystostomy. ${ }^{69}$ For difficult gallbladders, subtotal cholecystectomy performed by laparoscopy also yields better immediate outcomes with less bile leakage, as reported in a systematic review by Elshaer et al. ${ }^{70}$ The exact procedure of subtotal cholecystectomy was redefined by Strasberg in 2016. When only the top half or less of the gallbladder is removed, the term fundectomy is appropriate. Subtotal cholecystectomy is defined as removal of most of the gallbladder. Strasberg et al. ${ }^{67}$ have further clarified the subtypes of subtotal cholecystectomy: fenestrating versus reconstituting (based on whether a gallbladder remnant is created or not). The most common indications for subtotal cholecystectomy include severe acute cholecystitis (72.1\%), cholelithiasis in liver cirrhosis and portal hypertension (18.2\%), and empyema or a perforated gallbladder $(6.1 \%)$. $^{70}$ Currently, there is no series of subtotal cholecystectomies specifically performed on cirrhotic patients only, and most 
of the available studies have focused on severe inflammation, especially related to acute disease.

Similar to previous studies before the 21st century, Tokyo Guidelines 2018 (TG18), which is based on two systematic reviews, has suggested that subtotal cholecystectomy be considered for difficult situations as a bailout procedure to avoid serious damage to the bile duct or blood vessels. ${ }^{70-72}$ Regarding the timing of the publication of TG18, several relevant series related to subtotal cholecystectomy have also been published. ${ }^{73-75}$ While subtotal cholecystectomy has been recognized as a safe and alternative procedure for total cholecystectomy, the longterm outcome of patients is associated with the presence of retained stones in gallbladder remnants. The rate of retained stones varies from $4 \%$ to $15 \%{ }^{70,74}$ Although most retained stones can be retrieved by $\mathrm{ERCP}{ }^{73}$ some patients still have to undergo reoperations. ${ }^{75}$ In general, the rate of long-term complications after subtotal cholecystectomy is higher than that after total cholecystectomy. However, for patients who can "only" undergo subtotal cholecystectomy because of the local condition of the hepatocystic triangle, laparoscopic surgery provides better outcomes than open approach. $^{70}$

For cirrhotic patients, portal hypertension-associated variceal vessels and a bleeding tendency interfere with the performance of surgery. If good exposure of the hepatocystic triangle cannot be achieved, subtotal cholecystectomy under laparoscopy would be an alternative choice that might prevent patients from experiencing iatrogenic biliary injury, although possible long-term complications should be considered.

\section{Adjunct for hemostasis}

Portal hypertension-associated regional anatomic change, variceal vessels, and bleeding tendency may make cholecystectomy even more difficult. Several adjuncts have been applied in various fields of surgery. Several studies related to the application of harmonic scalpels in LC for cirrhotic patients have been published. While some studies revealed that harmonic scalpels may provide benefits with shorter operation times, less blood loss, and even fewer intraoperative GB ruptures, ${ }^{76,77}$ there was still one investigation that reported no significant benefit from harmonic scalpel use. ${ }^{78}$ Since all these studies were small in scale, these results might not be convincing. In addition, major complications after LC in the general population are low and acceptable in selected cirrhotic patients. To determine the significant difference under this circumstance, a study with an appropriate sample size would be necessary. In addition, the technique of using energy devices between different surgeons is variable, and this fact cannot be estimated in the aforementioned studies. Further investigation is necessary for this issue. In addition to energy devices, the application of other hemostatic adjuncts, such as oxidized regenerated cellulose and Floseal ${ }^{\circledR}$ (Baxter International, Inc., Deerfield, IL, USA) hemostatic matrix, has also been proposed in LC with positive impact. ${ }^{79,80}$

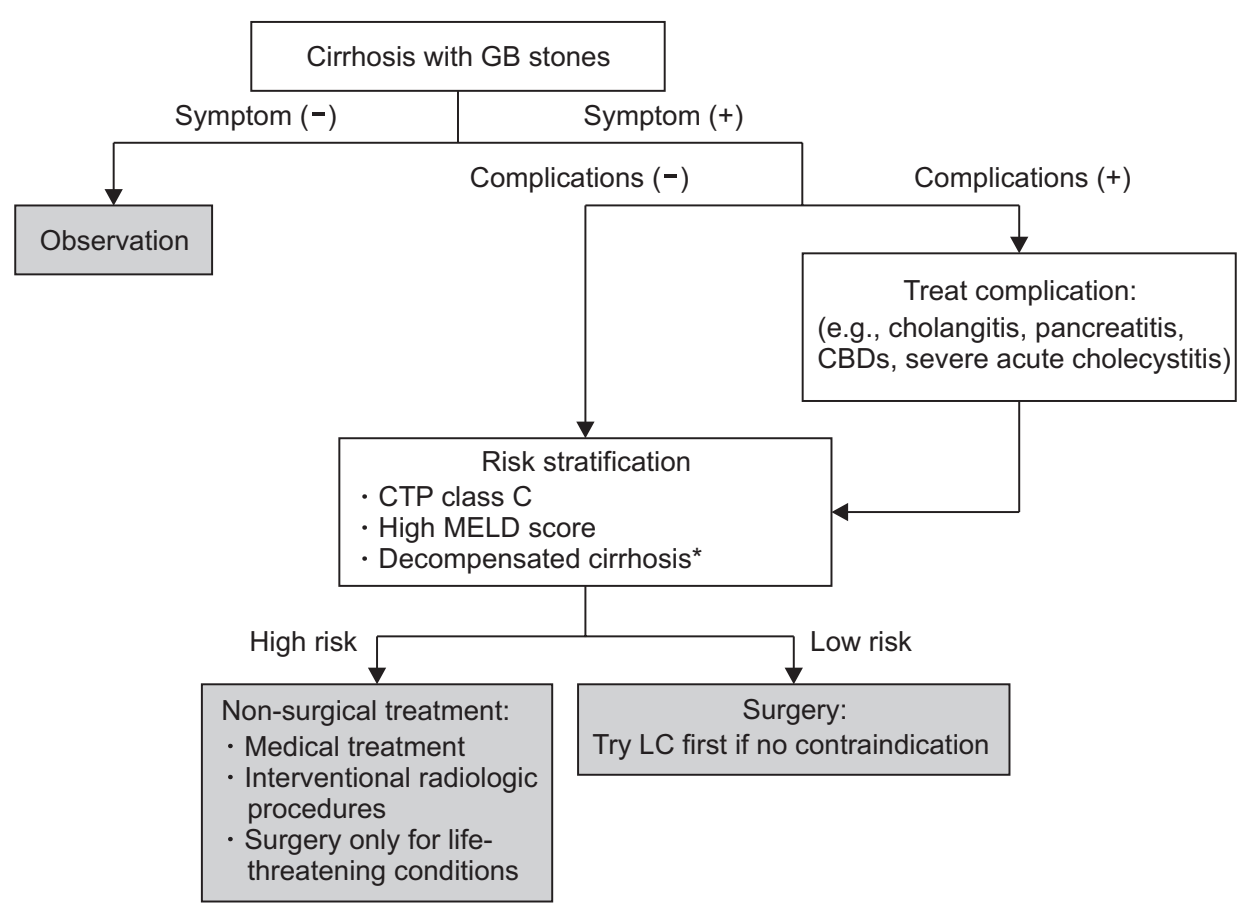

Fig. 2. Proposed flowchart for the management of cirrhotic patients with cholelithiasis.

$\mathrm{GB}$, gallbladder; $\mathrm{CBD}$, common bile duct stone; CTP, Child-TurcottePugh score; MELD, Model for EndStage Liver Disease; LC, laparoscopic cholecystectomy. *Decompensated cirrhosis: ascites and/or variceal bleeding occurrence. ${ }^{81,82} \mathrm{~A}$ meticulous evaluation should be performed, and surgery is only indicated when the patient is stabilized. 


\section{LIMITATIONS}

Although most of the current evidence recommends LC as a treatment for symptomatic cholelithiasis in cirrhotic patients without decompensation, we can see several pitfalls in all of the relevant studies listed in Table 1: (1) the majority of studies were retrospective; (2) most of the studies enrolled patients with CTP classes A and B; (3) most of the studies presented pooled results instead of subgroup analysis; and (4) the definitions of complications varied from study to study. While de Goede et al. ${ }^{31}$ tried to construct a higher level of evidence and conducted a systematic review with a meta-analysis of prospective trials, there were only four trials, from 1990 to 2011, with only 234 patients enrolled. This fact indicates that only a few prospective studies with limited patient numbers can be identified and that a large series of retrospective studies would be even more persuading. Although real-world data have also been published, ${ }^{60} \mathrm{LC}$ as a standard treatment is actually based on clinical studies providing no more than level II evidence. In addition to advances in surgical techniques, the modern anesthesiologic protocols, perioperative care, medical management of cirrhotic patients, and other minimally invasive procedures for complications of cirrhosis may all contribute to the outcome of cirrhosis. These synergistic effects cannot be assessed with the current evidence.

\section{CONCLUSION}

Based on currently available evidence, we propose a flow chart for the management of cirrhotic patients with GB stones (Fig. 2) ${ }^{81,82}$ The prevalence of cholelithiasis is relatively high in cirrhotic patients, and the surgical indications for LC in these patients are the same as those for noncirrhotic patients. Once the surgical indication is justified, meticulous preoperative evaluation is crucial. Advanced cirrhosis, such as CTP class C, is the contraindication for surgery. LC is the procedure of choice, just as for the general population. Postoperative management is also particularly important due to the relatively high, although acceptable, rate of complications.

\section{CONFLICTS OF INTEREST}

No potential conflict of interest relevant to this article was reported.

\section{ACKNOWLEDGEMENTS}

We would like to thank the Chang Gung Memorial Hospital for supporting our research (CMRPG3D0281).

\section{ORCID}

Shang Yu Wang https://orcid.org/0000-0003-1514-3015 Chun Nan Yeh https://orcid.org/0000-0003-1455-092X Yi Yin Jan https://orcid.org/0000-0003-4287-1245 Miin Fu Chen https://orcid.org/0000-0001-6422-807X

\section{REFERENCES}

1. Benvegnù L, Noventa F, Chemello L, Fattovich G, Alberti A. Prevalence and incidence of cholecystolithiasis in cirrhosis and relation to the etiology of liver disease. Digestion 1997;58:293-298.

2. Hung YL, Chong SW, Cheng CT, et al. Natural course of acute cholecystitis in patients treated with percutaneous transhepatic gallbladder drainage without elective cholecystectomy. J Gastrointest Surg 2020;24:772-779.

3. Lammert F, Gurusamy K, Ko CW, et al. Gallstones. Nat Rev Dis Primers 2016;2:16024.

4. Acalovschi M, Blendea D, Feier C, et al. Risk factors for symptomatic gallstones in patients with liver cirrhosis: a case-control study. Am J Gastroenterol 2003;98:1856-1860.

5. Sheen IS, Liaw YF. The prevalence and incidence of cholecystolithiasis in patients with chronic liver diseases: a prospective study. Hepatology 1989;9:538-540.

6. Acalovschi M. Gallstones in patients with liver cirrhosis: incidence, etiology, clinical and therapeutical aspects. World J Gastroenterol 2014;20:7277-7285.

7. Coelho JC, Slongo J, Dambroski Silva A, et al. Prevalence of cholelithiasis in patients subjected to liver transplantation for cirrhosis. J Gastrointestin Liver Dis 2010;19:405-408.

8. Hu JH, Chen MY, Yeh CT, Chiu WN, Chiang MS, Chang ML. Effects of gender and age on prevalence of cholelithiasis in patients with chronic $\mathrm{HCV}$ infection: a community-based cross-sectional study in an HCV-hyperendemic area. Medicine (Baltimore) 2018;97:e10846.

9. Morse EE. Mechanisms of hemolysis in liver disease. Ann Clin Lab Sci 1990;20:169-174.

10. Li CP, Hwang SJ, Lee FY, et al. Evaluation of gallbladder motility in patients with liver cirrhosis: relationship to gallstone formation. Dig Dis Sci 2000;45:1109-1114.

11. Acalovschi M, Dumitrascu DL, Nicoara CD. Gallbladder contractility in liver cirrhosis: comparative study in patients with and without gallbladder stones. Dig Dis Sci 2004;49:17-24. 
12. Loreno M, Travali S, Bucceri AM, Scalisi G, Virgilio C, Brogna A. Ultrasonographic study of gallbladder wall thickness and emptying in cirrhotic patients without gallstones. Gastroenterol Res Pract 2009;2009:683040.

13. Ticho AL, Malhotra P, Dudeja PK, Gill RK, Alrefai WA. Intestinal absorption of bile acids in health and disease. Compr Physiol 2019;10:21-56.

14. Dosch AR, Imagawa DK, Jutric Z. Bile metabolism and lithogenesis: an update. Surg Clin North Am 2019;99:215-229.

15. Carey MC. Pathogenesis of gallstones. Am J Surg 1993;165: 410-419.

16. Vítek L, Carey MC. Enterohepatic cycling of bilirubin as a cause of 'black' pigment gallstones in adult life. Eur J Clin Invest 2003;33:799-810.

17. Périssat J, Collet D, Belliard R, Desplantez J, Magne E. Laparoscopic cholecystectomy: the state of the art. A report on 700 consecutive cases. World J Surg 1992;16:1074-1082.

18. Lee YT, Sung J. Choledocholithiasis. In: Baron TH, Kozarek R, Carr-Locke DL, eds. ERCP. Philadelphia: Elsevier Inc, 2008:357-366.

19. Dunnington G, Alfrey E, Sampliner R, Kogan F, Putnam C. Natural history of cholelithiasis in patients with alcoholic cirrhosis (cholelithiasis in cirrhotic patients). Ann Surg 1987;205:226-229.

20. Maggi A, Solenghi D, Panzeri A, et al. Prevalence and incidence of cholelithiasis in patients with liver cirrhosis. Ital J Gastroenterol Hepatol 1997;29:330-335.

21. Castaing D, Houssin D, Lemoine J, Bismuth H. Surgical management of gallstones in cirrhotic patients. Am J Surg 1983;146:310-313.

22. Lamberts MP. Indications of cholecystectomy in gallstone disease. Curr Opin Gastroenterol 2018;34:97-102.

23. Simons-Linares CR, Romero-Marrero C, Jang S, et al. Clinical outcomes of acute pancreatitis in patients with cirrhosis. Pancreatology 2020;20:44-50.

24. Mashiana HS, Dhaliwal AS, Sayles H, et al. Endoscopic retrograde cholangiopancreatography in cirrhosis: a systematic review and meta-analysis focused on adverse events. World J Gastrointest Endosc 2018;10:354-366.

25. Okamuro K, Cui B, Moazzez A, et al. Laparoscopic cholecystectomy is safe in emergency general surgery patients with cirrhosis. Am Surg 2019;85:1146-1149.

26. Kangilaski J. Cholecystectomy hazardous in patient with cirrhosis. JAMA 1981;246:15.

27. Bloch RS, Allaben RD, Walt AJ. Cholecystectomy in patients with cirrhosis: a surgical challenge. Arch Surg 1985;120:669672 .

28. Cobb WS, Heniford BT, Burns JM, Carbonell AM, Matthews $\mathrm{BD}$, Kercher KW. Cirrhosis is not a contraindication to laparoscopic surgery. Surg Endosc 2005;19:418-423.

29. Lopez-Delgado JC, Ballus J, Esteve F, et al. Outcomes of abdominal surgery in patients with liver cirrhosis. World J Gastroenterol 2016;22:2657-2667.

30. Mansour A, Watson W, Shayani V, Pickleman J. Abdominal operations in patients with cirrhosis: still a major surgical challenge. Surgery 1997;122:730-735.

31. de Goede B, Klitsie PJ, Hagen SM, et al. Meta-analysis of laparoscopic versus open cholecystectomy for patients with liver cirrhosis and symptomatic cholecystolithiasis. Br J Surg 2013;100:209-216.

32. Schiff J, Misra M, Rendon G, Rothschild J, Schwaitzberg S. Laparoscopic cholecystectomy in cirrhotic patients. Surg Endosc 2005;19:1278-1281.

33. Perkins L, Jeffries M, Patel T. Utility of preoperative scores for predicting morbidity after cholecystectomy in patients with cirrhosis. Clin Gastroenterol Hepatol 2004;2:1123-1128.

34. Bingener J, Cox D, Michalek J, Mejia A. Can the MELD score predict perioperative morbidity for patients with liver cirrhosis undergoing laparoscopic cholecystectomy? Am Surg 2008;74:156-159.

35. Frye JW, Perri RE. Perioperative risk assessment for patients with cirrhosis and liver disease. Expert Rev Gastroenterol Hepatol 2009;3:65-75.

36. Delis S, Bakoyiannis A, Madariaga J, Bramis J, Tassopoulos $\mathrm{N}$, Dervenis C. Laparoscopic cholecystectomy in cirrhotic patients: the value of MELD score and Child-Pugh classification in predicting outcome. Surg Endosc 2010;24:407-412.

37. Currò G, Iapichino G, Melita G, Lorenzini C, Cucinotta E. Laparoscopic cholecystectomy in Child-Pugh class C cirrhotic patients. JSLS 2005;9:311-315.

38. Aranha GV, Kruss D, Greenlee HB. Therapeutic options for biliary tract disease in advanced cirrhosis. Am J Surg 1988;155:374-377.

39. Klimberg S, Hawkins I, Vogel SB. Percutaneous cholecystostomy for acute cholecystitis in high-risk patients. Am J Surg 1987;153:125-129.

40. Fernandes NF, Schwesinger WH, Hilsenbeck SG, et al. Laparoscopic cholecystectomy and cirrhosis: a case-control study of outcomes. Liver Transpl 2000;6:340-344.

41. Yeh CN, Chen MF, Jan YY. Laparoscopic cholecystectomy in 226 cirrhotic patients: experience of a single center in Taiwan. Surg Endosc 2002;16:1583-1587.

42. Tuech JJ, Pessaux P, Regenet N, Rouge C, Bergamaschi R, Arnaud JP. Laparoscopic cholecystectomy in cirrhotic patients. Surg Laparosc Endosc Percutan Tech 2002;12:227231.

43. Cucinotta E, Lazzara S, Melita G. Laparoscopic cholecystectomy in cirrhotic patients. Surg Endosc 2003;17:1958-1960.

44. da Silveira EB. Outcome of cirrhotic patients undergoing cholecystectomy: applying Bayesian analysis in gastroenterology. J Gastroenterol Hepatol 2006;21:958-962.

45. Curro G, Baccarani U, Adani G, Cucinotta E. Laparoscopic 
cholecystectomy in patients with mild cirrhosis and symptomatic cholelithiasis. Transplant Proc 2007;39:1471-1473.

46. Leandros E, Albanopoulos K, Tsigris C, et al. Laparoscopic cholecystectomy in cirrhotic patients with symptomatic gallstone disease. ANZ J Surg 2008;78:363-365.

47. Pavlidis TE, Symeonidis NG, Psarras K, et al. Laparoscopic cholecystectomy in patients with cirrhosis of the liver and symptomatic cholelithiasis. JSLS 2009;13:342-345.

48. Shaikh AR, Muneer A. Laparoscopic cholecystectomy in cirrhotic patients. JSLS 2009;13:592-596.

49. Hamad MA, Thabet M, Badawy A, et al. Laparoscopic versus open cholecystectomy in patients with liver cirrhosis: a prospective, randomized study. J Laparoendosc Adv Surg Tech A 2010;20:405-409.

50. Nguyen KT, Kitisin K, Steel J, et al. Cirrhosis is not a contraindication to laparoscopic cholecystectomy: results and practical recommendations. HPB (Oxford) 2011;13:192-197.

51. Malinchoc M, Kamath PS, Gordon FD, Peine CJ, Rank J, ter Borg PC. A model to predict poor survival in patients undergoing transjugular intrahepatic portosystemic shunts. Hepatology 2000;31:864-871.

52. Kamath PS, Wiesner RH, Malinchoc M, et al. A model to predict survival in patients with end-stage liver disease. Hepatology 2001;33:464-470.

53. Dolejs SC, Beane JD, Kays JK, Ceppa EP, Zarzaur BL. The model for end-stage liver disease predicts outcomes in patients undergoing cholecystectomy. Surg Endosc 2017;31:5192-5200.

54. Fleming MM, DeWane MP, Luo J, Zhang Y, Pei KY. Ascites: a marker for increased surgical risk unaccounted for by the model for end-stage liver disease (MELD) score for general surgical procedures. Surgery 2018;164:233-237.

55. Costa BP, Sousa FC, Serôdio M, Carvalho C. Value of MELD and MELD-based indices in surgical risk evaluation of cirrhotic patients: retrospective analysis of 190 cases. World J Surg 2009;33:1711-1719.

56. Yerdel MA, Tsuge H, Mimura H, Sakagami K, Mori M, Orita K. Laparoscopic cholecystectomy in cirrhotic patients: expanding indications. Surg Laparosc Endosc 1993;3:180-183.

57. Bittner R. The standard of laparoscopic cholecystectomy. Langenbecks Arch Surg 2004;389:157-163.

58. Poggio JL, Rowland CM, Gores GJ, Nagorney DM, Donohue $\mathrm{JH}$. A comparison of laparoscopic and open cholecystectomy in patients with compensated cirrhosis and symptomatic gallstone disease. Surgery 2000;127:405-411.

59. El-Awadi S, El-Nakeeb A, Youssef T, et al. Laparoscopic versus open cholecystectomy in cirrhotic patients: a prospective randomized study. Int J Surg 2009;7:66-69.

60. Chmielecki DK, Hagopian EJ, Kuo YH, Kuo YL, Davis JM. Laparoscopic cholecystectomy is the preferred approach in cirrhosis: a nationwide, population-based study. HPB (Ox- ford) 2012;14:848-853.

61. Laurence JM, Tran PD, Richardson AJ, Pleass HC, Lam VW. Laparoscopic or open cholecystectomy in cirrhosis: a systematic review of outcomes and meta-analysis of randomized trials. HPB (Oxford) 2012;14:153-161.

62. Clark JR, Wills VL, Hunt DR. Cirrhosis and laparoscopic cholecystectomy. Surg Laparosc Endosc Percutan Tech 2001;11:165-169.

63. Leone N, Garino M, De Paolis P, Pellicano R, Fronda GR, Rizzetto M. Laparoscopic cholecystectomy in cirrhotic patients. Dig Surg 2001;18:449-452.

64. Mancero JM, D’Albuquerque LA, Gonzalez AM, Larrea FI, de Oliveira e Silva A. Laparoscopic cholecystectomy in cirrhotic patients with symptomatic cholelithiasis: a casecontrol study. World J Surg 2008;32:267-270.

65. Lledó JB, Ibañez JC, Mayor LG, Juan MB. Laparoscopic cholecystectomy and liver cirrhosis. Surg Laparosc Endosc Percutan Tech 2011;21:391-395.

66. Polymeneas G, Theodosopoulos T, Stamatiadis A, Kourias E. A comparative study of postoperative adhesion formation after laparoscopic vs open cholecystectomy. Surg Endosc 2001;15:41-43.

67. Strasberg SM, Pucci MJ, Brunt LM, Deziel DJ. Subtotal cholecystectomy-"fenestrating" vs "reconstituting" subtypes and the prevention of bile duct injury: definition of the optimal procedure in difficult operative conditions. J Am Coll Surg 2016;222:89-96.

68. Madding GF. Subtotal cholecystectomy in acute cholecystitis. Am J Surg 1955;89:604-607.

69. Katsohis C, Prousalidis J, Tzardinoglou E, et al. Subtotal cholecystectomy. HPB Surg 1996;9:133-136.

70. Elshaer M, Gravante G, Thomas K, Sorge R, Al-Hamali S, Ebdewi H. Subtotal cholecystectomy for "difficult gallbladders": systematic review and meta-analysis. JAMA Surg 2015;150:159-168.

71. Wakabayashi G, Iwashita Y, Hibi T, et al. Tokyo Guidelines 2018: surgical management of acute cholecystitis: safe steps in laparoscopic cholecystectomy for acute cholecystitis (with videos). J Hepatobiliary Pancreat Sci 2018;25:73-86.

72. Henneman D, da Costa DW, Vrouenraets BC, van Wagensveld BA, Lagarde SM. Laparoscopic partial cholecystectomy for the difficult gallbladder: a systematic review. Surg Endosc 2013;27:351-358.

73. Tay WM, Toh YJ, Shelat VG, et al. Subtotal cholecystectomy: early and long-term outcomes. Surg Endosc 2020;34:45364542.

74. Kohga A, Suzuki K, Okumura T, et al. Calculus left in remnant gallbladder cause long-term complications in patients undergoing subtotal cholecystectomy. HPB (Oxford) 2019;21:508-514.

75. van Dijk AH, Donkervoort SC, Lameris W, et al. Short- and 
long-term outcomes after a reconstituting and fenestrating subtotal cholecystectomy. J Am Coll Surg 2017;225:371-379.

76. El Nakeeb A, Askar W, El Lithy R, Farid M. Clipless laparoscopic cholecystectomy using the Harmonic scalpel for cirrhotic patients: a prospective randomized study. Surg Endosc 2010;24:2536-2541.

77. Bessa SS, Abdel-Razek AH, Sharaan MA, et al. Laparoscopic cholecystectomy in cirrhotics: a prospective randomized study comparing the conventional diathermy and the harmonic scalpel for gallbladder dissection. J Laparoendosc Adv Surg Tech A 2011;21:1-5.

78. Rajnish K, Sureshkumar S, Ali MS, Vijayakumar C, Sudharsanan S, Palanivel C. Harmonic scalpel-assisted laparoscopic cholecystectomy vs. conventional laparoscopic cholecystectomy: a non-randomized control trial. Cureus 2018;10:e2084.

79. Masci E, Faillace G, Longoni M. Use of oxidized regenerated cellulose to achieve hemostasis during laparoscopic chole- cystectomy: a retrospective cohort analysis. BMC Res Notes 2018;11:239.

80. Sartelli M, Catena F, Biancafarina A, et al. Use of Floseal hemostatic matrix for control of hemostasis during laparoscopic cholecystectomy for acute cholecystitis: a multicenter historical control group comparison (the GLA study gelatin matrix for acute cholecystitis). J Laparoendosc Adv Surg Tech A 2014;24:837-841.

81. de Franchis R. Evolving consensus in portal hypertension: report of the Baveno IV Consensus Workshop on methodology of diagnosis and therapy in portal hypertension. J Hepatol 2005;43:167-176.

82. Sargenti K, Prytz H, Nilsson E, Kalaitzakis E. Predictors of mortality among patients with compensated and decompensated liver cirrhosis: the role of bacterial infections and infection-related acute-on-chronic liver failure. Scand J Gastroenterol 2015;50:875-883. 